\title{
Agricultural jobs in the eyes of college students
}

\begin{abstract}
There is now a renewed interest in agriculture. The Malaysian government wants to revitalize the agriculture sector to become the third engine of growth after the services and manufacturing sectors. For that matter, a total of RM11.7 billions is allocated under the 9th. Malaysian Plan (9MP) to transform agriculture sector into a modern, dynamic and competitive sector. With the emphasis given by the government, Malaysia has to have her younger generation who are willing to venture into agricultural industries. But, is Malaysian younger generation willing to venture into agriculture? The study aimed at determining the young generation's (students) interest in agriculture related jobs and their perceptions about occupations in agriculture. The findings indicated that students were moderately interested in agriculture related jobs $(\mathrm{M}=2.68 ; \mathrm{SD}=.86)$. Their perceptions about jobs in agriculture were moderate $(\mathrm{M}=3.41, \mathrm{SD} .=.97)$. Based on the study actions have to be taken to ensure that young people would want to venture into agricultural careers. Even though they were interested in agriculture but their moderately positive perceptions about agriculture will hinder their movement into agricultural industries.
\end{abstract}

Keyword: Career Interest, College Students' Career Choices, Attitudes toward Agriculture 